\title{
Study on node-flow distribution method considering the non-revenue water
}

\author{
Chunsheng Zhang ${ }^{1}$, Jianjun Wang ${ }^{2,3}$, Tong Wang ${ }^{1,4}$, Hang $\mathrm{Li}^{1}$, Yang Feng ${ }^{1}$, \\ Hao $\mathrm{Fu}^{1}$, Ming Zhao ${ }^{5}$, Dong Yang ${ }^{4}$, \\ ${ }^{1}$ School of Environmental Science and Engineering, Chang'an University, Xi'an, 710054, China \\ ${ }^{2}$ School of Civil Engineering, Shandong University, Jinan, 250100, China \\ ${ }^{3}$ Jinan Water Group Co., Ltd, Jinan, 250000, China \\ ${ }^{4}$ Tianjin Sambo Water Technology Co., Ltd, Tianjin, 300070, China \\ ${ }^{5}$ School of Municipal and Environmental Engineering, Harbin Institute of Technology, Harbin, \\ 150001, China \\ *email: zhming1188@126.com
}

\section{Keywords: Hydraulic model; Node-flow distribution; NRW; Business and sales data}

Abstract. In order to solve the problems of the inaccuracy of node-flow distribution in the hydraulic model of water supply pipe network, a better method to distribute node-flow was presented. The node-flow is consisted of marketing node-flow and non-revenue water. The marketing node-flow was confirmed by the data of business and sales. In addition, according to various water supplied area, the non-revenue water was distributed to node. Compared with other methods, the node-flow distribution method is well-positioned and reasonable assignment, hereby meeting the needs of practical engineering and production.

\section{Introduction}

At present, the theory study of the hydraulic calculation method in water supply pipe network has improved, however, the actual effect is not ideal in engineering application, one of the significant reason is that the method of node-flow distribution is not accurate. The inaccuracy of node-flow distribution can't accurately reflect the actual network operation condition in the micro hydraulic model of water supply network [1]. In order to get more accurate results, many scholars studied the method of node-flow distribution in the past. The water area is divided into blocks, then finding a typical node in each block as a water node (Aoyama T, et al) [2]. Though different methods has partly improved the accuracy of node-flow distribution, but the node-flow distribution didn't consider the Non-Revenue Water (NRW) [3], thus leading to the result can't precisely reflect the integrated water distribution.

In the view of the inaccuracy of node-flow distribution at hydraulic model of water supply network, combined with the comparatively perfect technology of Geography Information System (GIS) [4], we set up a hydraulic model using the $W N W^{\circledR}$ software, and add the module of node-flow distribution, realized the function of distributing flow at water supply network. The node-flow is consisted of two parts, one part is marketing node flow, which is obtained from water meter using water meter layer in GIS, the other part is non-revenue node-flow, which is distributed to the node in the block[5] using the method of the along line flow.

\section{The calculation of market node-flow}

Determine the user types of water and the hourly variation coefficient

The types of water is counted in the operating charging database. Aiming at various types, the method of field test is respectively applied to determine various types of hourly variation coefficient. If 
there are too much water types, incorporate the types of using less water. Each type has the distinction between holiday and workday. Each type select 3 to 5 representatives to test, and solve the average value of representative's variation coefficient. The specific test method as follows: uses remote automatic meter to record the water volume of user, and records the cumulative flow at every hour, continuous measure 24 hours, then calculate water volume at each hour. The formula of hourly variation coefficient as follows:

$$
K_{i j}=\frac{Q_{i j}}{\frac{1}{2} q_{i}}
$$

In the type (1): $K_{i j}$ is a variation coefficient of $i$ type at $\mathrm{j}$ hour; $Q_{i j}$ is the water supply volume of $i$ type at $j$ hour; $Q_{i}$ is the 24 hours accumulative water of $i$ type at $j$ hour.

Position the node of using water

Based on GIS figure of water supply network, the method of "meter tracing" is used to position the node. Firstly, the water meter is moved from the small diameter pipe up to the large diameter pipeline; secondly, delete the terminal of pipeline and node. Step by step back until meet the pipe which diameter is more than $200 \mathrm{~mm}$; thirdly, count the types the volume of using water in the node. When we confirm the water meter and the hourly variation coefficient, we can calculate the node-water at every hour according to the operating charge data. Marketing node-flow include various types of flow.

\section{The calculation of NRW}

The definition of NRW

NRW is the difference between the volume of water put into a water distribution system and the volume that is billed to customers.

NRW is comprised of three components [6]:

(1) Physical losses include leakage from all parts of the distribution system and overflows at the utility's storage tanks. They can be caused by poor operations and maintenance, the lack of active leakage control, and poor quality of underground assets;

(2) Commercial losses include customer meter under-registration, data-handling errors, and theft of water in various forms;

(3) Unbilled authorized consumption includes water used by the utility for operational purposes, water used for firefighting, and water provided for free to certain consumer groups.

When we establish hydraulic model, in order to balance the input and output of water in the water network system, the non-revenue water should be added to the output of water. The distributional plan, which distribute the non-revenue water to the node of network according to block, is more accurate and practical.

The method to distribute the NRW

The NRW should be distributed to the node within model in order to keep balance between water supply and demand. The along line flow method is used to distribute the NRW to each node of network.

(1) Assuming water is distributed equably to all the main, as a result, the formula to calculate the unit specific discharge is shown as the following:

$$
\mathrm{qs}=\frac{Q}{\sum_{l}}
$$

In the type (2): $Q$ is the NRW in an area; $\Sigma l$ is the total length in an area; $Q s$ is the specific discharge in an area.

(2) The formula to calculate the along line flow according to the specific discharge as the following:

$$
\mathrm{q}_{i}=q s \times l_{i}
$$


In the type (3): $\mathrm{ql}_{i}$ is the along line flow of the pipe $i$; $l_{i}$ is the equivalent length of the pipe $i$.

(3) The formula to calculate the node flow from the along line flow as the following:

$$
q_{i}=0.5 \times \sum_{j=1}^{N} q l_{j}
$$

In the type (4): $q_{i}$ is the NRW in the node $i ; N$ is the number of the pipe connected to the node $i$; $q l_{j}$ is the along line flow of the $j$ pipe which is connected to node $i$.

Node-flow is the sum of marketing node-flow and the non-revenue node-flow. The calculating diagram of NRW The calculating diagram of NRW as the Fig.1:

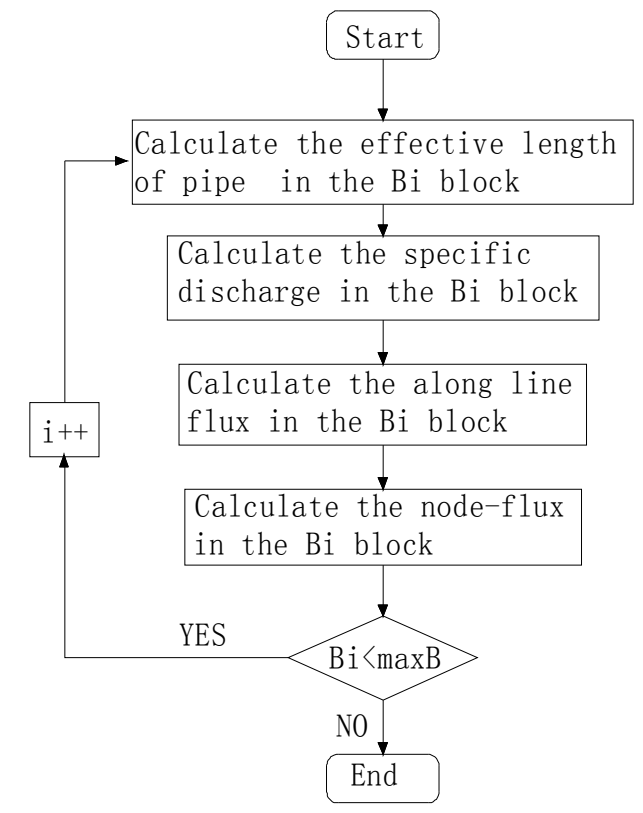

Fig. 1 The calculating diagram of NRW

\section{Application}

The type of water and the average water demand are solved using the method of "meter tracing". The number of pump station and water plants are 25 in the J city. The whole network is divided into 14 blocks, and each block's NRW can be solved by the difference between water supply and sale of water at pump station or water plant. The NRW in different regions in mean time are shown in table 1.

There are 18 kinds of abbreviation in the business charge database of the city J, represented 18 types of water. Too many types will increase the workload of field test, also does not help to improve the accuracy, therefore combine the types of water, according to their similarity. The types of water are residents, office, school, business, etc. after combined with water type, and each type of water has the difference between holiday and workday. Variation coefficient of water are solved through field measurement. Part of the change of water type curve as shown in figure 2 to figure 5. 
Tab 1 The NRW in each region

\begin{tabular}{cccc}
\hline The Areas & $\begin{array}{c}\text { NRW in Mean Time } \\
{\left[\mathrm{m}^{3} / \mathrm{h}\right]}\end{array}$ & The Areas & $\begin{array}{c}\text { NRW in Mean } \\
\text { Time }\left[\mathrm{m}^{3} / \mathrm{h}\right]\end{array}$ \\
\hline The area of BQ & 719.93 & The area of XS & 112.34 \\
The area of DLZ & 246.21 & The area of & 768.75 \\
The area of & 330.08 & The area of DPQ & 202.82 \\
The area of JFQ & 106 & The area of LXC & 510.56 \\
The area of JJL & 193.52 & The area of GZ & 57.08 \\
The area of LXXZ & 1265.53 & The area of LZY & 144.11 \\
The area of LN & 455.37 & The area of LDB & 153.31 \\
\hline
\end{tabular}

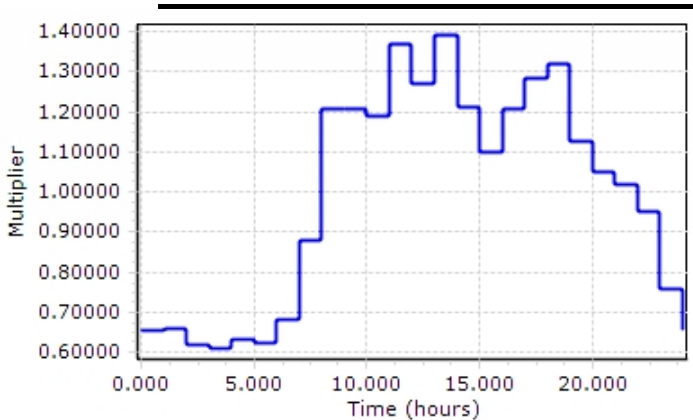

Fig.2 Curve of office class's water

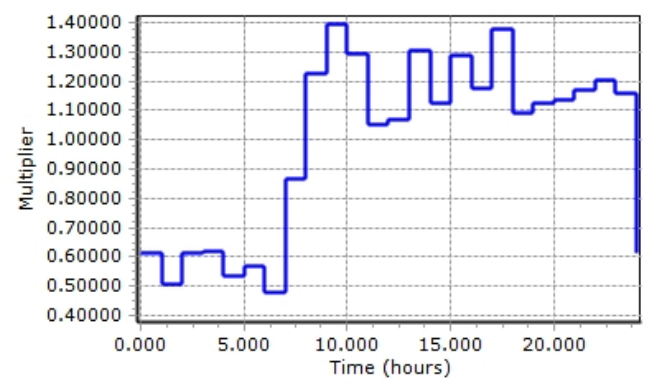

Fig.4 Curve of residents class's water

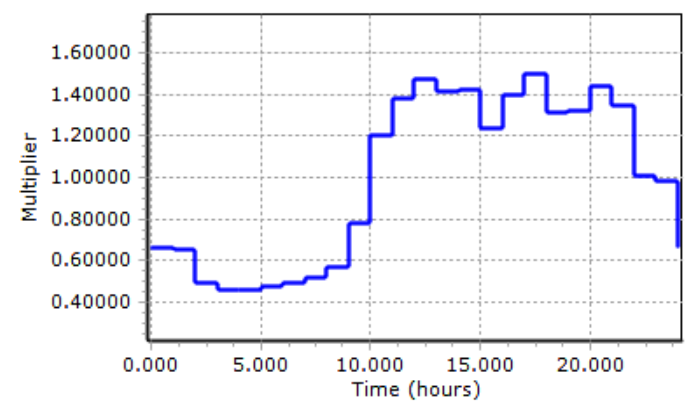

Fig.3 Curve of service class's water

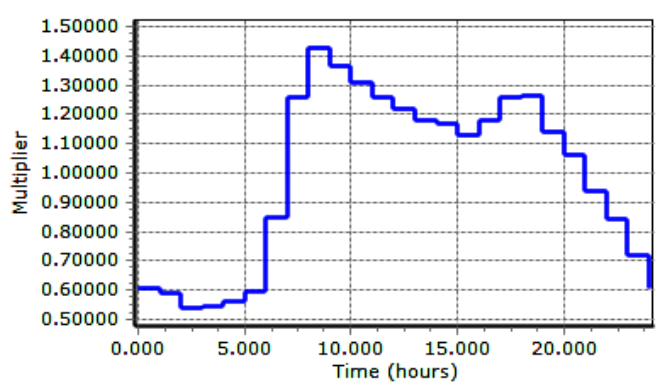

Fig.5 Curve of hospital class's water

After distributing flow by the algorithm, we can obtain the adjusted result though the calculation of hydraulic adjustment by $W N W^{\circledR}$ software. The simulation results of node pressure and flow should be compared with the pressure and flow data from actual testing point. The flow's relative error in the monitoring are shown in table 2; Pressure's relative error in the monitoring is shown in table 3.

Tab.2 The relative error of flow monitoring point

\begin{tabular}{cccccccc}
\hline \multirow{2}{*}{$\begin{array}{c}\text { The number of } \\
\text { flow monitoring }\end{array}$} & $\begin{array}{c}\text { 00th } \\
\text { hour }\end{array}$ & $\begin{array}{c}\text { 08th } \\
\text { hour }\end{array}$ & $\begin{array}{c}\text { 12th } \\
\text { hour }\end{array}$ & $\begin{array}{c}\text { 16th } \\
\text { hour }\end{array}$ & $\begin{array}{c}\text { 20th } \\
\text { hour }\end{array}$ & $\begin{array}{c}\text { 24th } \\
\text { hour }\end{array}$ & $\begin{array}{c}\text { Relative error } \\
\text { in average } \\
{[\%]}\end{array}$ \\
\hline 1 & 1.271 & 0.674 & 0.133 & 0.508 & 0.100 & 0.065 & 0.458 \\
2 & 5.639 & 3.476 & 3.23 & 3.202 & 3.239 & 3.552 & 3.723 \\
3 & 0.002 & 0.0004 & 0.0002 & 0.001 & 0.0005 & 0.004 & 0.001 \\
4 & 5.995 & 8.078 & 9.028 & 7.745 & 10.612 & -6.447 & 7.984 \\
5 & 1.774 & 0.577 & 0.678 & 0.389 & 0.188 & 0.679 & 0.714 \\
6 & 2.490 & 1.24 & 1.055 & 3.431 & 1.360 & 2.269 & 1.974 \\
7 & 0.015 & 0.006 & 0.005 & 0.899 & 0.005 & 0.025 & 0.159 \\
8 & 0.002 & 0.002 & 0.002 & 0.002 & 0.002 & 0.008 & 0.003 \\
9 & 0.252 & 2.122 & 2.700 & 0.002 & 3.519 & 6.696 & 2.548 \\
10 & 0.326 & 0.327 & 0.236 & 1.812 & 0.135 & 0.114 & 0.492 \\
11 & 0.032 & 4.159 & 3.477 & 0.236 & 1.692 & 4.407 & 2.334 \\
\hline
\end{tabular}


Tab.3 The relative error at pressure monitoring point

\begin{tabular}{ccccccc}
\hline $\begin{array}{c}\text { The number of } \\
\text { pressure } \\
\text { monitoring }\end{array}$ & $\begin{array}{c}\text { 00th } \\
\text { hour }\end{array}$ & $\begin{array}{c}\text { 08th } \\
\text { hour }\end{array}$ & $\begin{array}{c}\text { 12th } \\
\text { hour }\end{array}$ & $\begin{array}{c}\text { 16th } \\
\text { hour }\end{array}$ & $\begin{array}{c}\text { 20th } \\
\text { hour }\end{array}$ & $\begin{array}{c}\text { Relative error in } \\
\text { average [\%] }\end{array}$ \\
\hline 1 & -3.81 & 2.83 & 3.82 & -0.32 & 3.68 & 2.892 \\
2 & -1.29 & -3.79 & -1.47 & -3.72 & -3.99 & 3.052 \\
3 & -0.56 & -1.96 & 0.21 & -0.34 & 0.6 & 0.734 \\
4 & -1.16 & -1.53 & 0.01 & -0.68 & 0.18 & 0.712 \\
5 & 2.05 & -1.23 & 0.33 & -2.2 & -0.15 & 1.192 \\
6 & -1.12 & 1.66 & 0.68 & -1.87 & -1.3 & 1.326 \\
7 & 1.09 & 1.54 & 1.73 & 0.27 & 0.87 & 1.1 \\
8 & 0.83 & 0.29 & 0.13 & -1.48 & 0.5 & 0.646 \\
9 & -1.21 & -0.99 & 0.15 & -0.67 & -0.31 & 0.666 \\
10 & 2.49 & -0.95 & 0.28 & 1.34 & 1.43 & 1.298 \\
11 & -1.27 & 0.35 & 0.74 & -1.38 & 0.16 & 0.78 \\
\hline
\end{tabular}

The calibration of flow and pressure in the hydraulic model is successful seen from table 2 and table 3 , and it is proved that the distribution of the node-flow method is consistent with the actual situation. The author thinks that the reason as described below:

(1) The method of "meter tracing", using the GIS technology, to locate the node is more accurate than the method using municipal figure to select node, avoiding the blindness of determine node in the past;

(2) The distribution method considering to the NRW is consistent with the actual situation;

(3) Field test method is used to determine the various types of variation coefficient, avoiding the subjectivity, so as to improve the accuracy of node-flow calculation furthest.

\section{Conclusion}

The allocation method is proposed in this paper to improve the accuracy of the network model, greatly broadens the application range of the adjustment of pipe network, this method can accurately grasp the real working condition of the pipe network, and provides support for hydraulic and quality analysis through the model. In addition, this method is helpful to realize the seamless connection between hydraulic model and the GIS of water supply pipe, facilitate water department to realize information management.

\section{References}

[1] S. Ates: App. Math. Mod. Forum Vol. 40 (2016), p. 966-983

[2] Aoyama T, Kawamoto S: Wat. Sup. Forum Vol. 17 (1999), p.269-275

[3] V.Kanakoudis, K.Gonelas: Pro. Eng. Forum Vol. 89 (2014), p.958-966

[4] J. Wright, J. Liu, R. Bain, A. Perez, J. Crocker, J. Bartramb, S. Gundry: Sci of the Tot Env. Forum Vol. 485 (2014), p. 643-652

[5] P. Gomez, F. Cubillo, F.J. Martin: 12th International Conference on Computing and Control for the Water Industry (Elsevier Procedia, Italy 2014).

[6] C.v.d. Berg: Uti Pol. Forum Vol. 36 (2015), p. 71-78 